\title{
Opportunities and Challenges of International e-Commerce in the Pilot Areas of China
}

\author{
Jing Wang ${ }^{1}$ \\ ${ }^{1}$ Development of International Business, Zhejiang Financial College, Hangzhou, Zhejiang, China \\ Correspondence: Jing Wang, Development of International Business, Zhejiang Financial College, 118 Xueyuan \\ Street, Hangzhou, Zhejiang, China. E-mail: vividou@126.com
}

Received: August 19, 2014

Accepted: October 28, 2014 Online Published: November 24, 2014

doi:10.5539/ijms.v6n6p141

URL: http://dx.doi.org/10.5539/ijms.v6n6p141

\begin{abstract}
International e-commerce is expanding rapidly in China, and this rate of growth is expected to continue into the future. Pilot projects for importation by e-commerce were launched by the Chinese government in March 2014 . These pilots took place in six cities and were intended to encourage international e-commerce. International e-commerce bonded import pilot areas are unprecedented around the world, and the challenges and opportunities of this new method of commerce need to be identified and clarified for all parties involved. This paper examines the trends and characteristics of cross-border e-commerce development in China and the challenges and opportunities for overseas suppliers. Using a SWOT analysis matrix, strategies are suggested for overseas e-commerce businesses who intend to profit from Chinese bonded import pilots.
\end{abstract}

Keywords: Cross-border e-commerce, bonded import pilots, offshore online shopping, SWOT analysis matrix, marketing challenges, marketing opportunities

\section{Introduction}

According to The Institute of Forward-Looking Industry's definition, international e-commerce refers to international business transactions between different countries, making deals and transactions through an e-commerce platform, and delivering goods through cross-border planning and management agreements. In practical terms, it mainly consists of B2B (Business to Business), B2C (Business to Consumer) and C2C (Consumer to Consumer) arrangements. International e-commerce retailing refers to $\mathrm{B} 2 \mathrm{C}$ and $\mathrm{C} 2 \mathrm{C}$, in which customs purchase directly from an overseas e-commerce platform or through an individual buying proxy. In recent years, the buying momentum of the Chinese consumer to purchase products through various overseas shopping sites has experienced explosive growth. In 2013, more than \$11 billion (US) was spent on overseas e-commerce transactions.

Because of the unique nature of international e-commerce, the current policy and regulatory environment has been unable to keep pace with the development of this market. Partially due a lack of confidence in the quality of domestic products, Chinese consumers are driving the rapid growth of international online shopping, and will likely continue to do so for a long period of time. It continues to be hindered by undependable product quality and after-sales service.

Recently, the Chinese government showed great interest in international e-commerce development and strongly promoted the industry. In August 2013, the Chinese State Council issued a notice to support international e-commerce, which included the following:

- the establishment of an e-commerce outlet customs control mode,

- the establishment of an appropriate inspection and supervision model,

- $\quad$ support for normal businesses to engage in foreign exchange,

- encouragement of banking institutions and payment institutions to provide payment services for international e-commerce,

- the adaption of a taxation policy; and,

- the establishment of the export credit system. 
On March 21, 2014, the Chinese Customs Department implemented an e-commerce pilot program which identified six cities (Shanghai, Hangzhou, Ningbo, Zhengzhou, Guangzhou and Chongqing) as bonded import pilot areas for e-commerce, specializing in international e-commerce. It is predicted that international e-commerce will continue to exhibit explosive growth with the support of the Chinese government and the establishment of the pilot areas. However, there are no adaptable import regulations for these pilot areas, and it is unlikely there will be a significant breakthrough in policy in the short-term, such as more flexible measures or regulation.

With regard to online businesses overseas, the establishment of pilot areas provides an advantage to the above-mentioned six cities, in terms of costs, logistics and ease of customs clearance, which may increase market competiveness to develop the Chinese market.

\section{Literature Review}

\subsection{Studies on International e-Commerce}

Wirtz and Kleineicken (2000), Zott and Amit (2011), Zhang, Williams and E. Polychronakis(2012) identified the types business models of e-commerce and evaluate the efficient of them by different methods. Mendling and Neumann (2005) distinguished e-business by their type of revenue generation using revenue model. Martinez and Williams (2010) offers insights into the development of e-commerce across countries utilized competing theories to examine information and communication technology (ICT) adoption.

\subsection{Studies on International e-Commerce Strategies}

Singh, Alhorr and Kim (2010) apply the concept of "adaptive strategies" to global e-commerce practices, offering new insights by exploring the impact of external environment for strategic global e-commerce decisions settings. Van Slyke, Lou, Belanger and Sridhar (2010) use innovation adoption theory on culture and information technology to examine the question of whether culture influences consumer's decisions to shopping online, and results indicate that national culture does influence intentions to purchase online. Gupta, Iyer and Weisskirch (2010) deal with how culture of a particular country influence the online shopping behavior and how global companies provide customized services to expand e-commerce in different cultural contexts. BIERON \& AHMED (2012) illustrate the international law issues that have arisen from the proliferation of cross-border e-commerce using the experience of eBay.

\subsection{Studies on International e-Commerce Development in China}

$\mathrm{Wu}(2006)$ investigates the inherent characteristics of international e-commerce in China. Tu (2013), Li (2008) and Gong (2009) take research on the supply chain in e-commerce in China. Hu (2013), Guo (2008) and Fu (2013) carry out research on global strategy for Chinese e-commerce companies and provide suggestions for foreign trade companies in China who want to put their business online. Xiong (2007) analyzes the price dispersion phenomenon of online shopping market and provides the strategies for online vendors in China.

\section{Methodology}

Although international e-commerce has been researched from different perspectives, such as the consumer point of view, the company point of view and the global perspective of the industry, there has been insufficient research on the driven force of international e-commerce buyers in China in different periods, and lack of research on international e-commerce development in pilot areas specifically.

Therefore, this article attempts to figure out the basic premise of China's international e-commerce development, make predictions about the future development of international e-commerce based on an analysis of primary and secondary data, and provide an analysis of what the pilot policy will bring to companies, and what should companies focus on if they want to benefit from the rapid development of e-commerce in China.

Primary data was gathered over 20 months of regular interviews with decision-making teams and individuals from the International e-Commerce Industry Park, China's first international e-commerce industrial park, established in Hangzhou in August 2012. Secondary data was taken from reports published by various reports published by McKinsey, Boci Research, I-World Electronic Retailing Research, The First Finance and Economics Research, and China Business Network, research institutions and information released by the Chinese government.

Innovation diffusion theory, value chain theory to deduction, and the SWOT model were used in the analysis of the data. Several practical significance strategies have been given at the end of the study. 


\section{Objectives}

It is of particular importance to maximize the benefits of the pilot areas and capture the Chinese market augmented by the international e-commerce development driven by the Chinese government, as the Chinese retail market represents a significant piece of the overseas e-commerce market. Therefore, a deep understanding of the market, such as the policies and the purchasing power and the desire of consumers, is required. This paper primarily attempts to examine the following:

- the phases of international e-commerce development, the driving force of buyers and the characteristics of competitive advantage of sellers at each phase,

- how the latest policy and the establishment of pilot areas have influence on international e-commerce and what are the points to focus on in the future,

- identify the cross-border e-commerce opportunities and challenges within pilot areas which would be the hot spot in the industry of e-commerce in China; and,

- $\quad$ suggest an international e-commerce supplier development strategy.

\section{Presentations and Discussions of Findings}

\subsection{International e-Commerce Market Profile and Features}

\subsubsection{Market Profile}

China's online shopping market has developed very quickly. Online shopping users, the total amount of online shopping and online shopping overseas are all showing strong growth momentum.

As of December 2013, China's online shopping users reached 301.89 million, an increase of 59.87 million, representing a $24.7 \%$ increase. Utilization rates increased from $42.9 \%$ to $48.9 \%$ (See figure 1). This rapid growth of online consumers illustrates a strong user base and huge market potential.

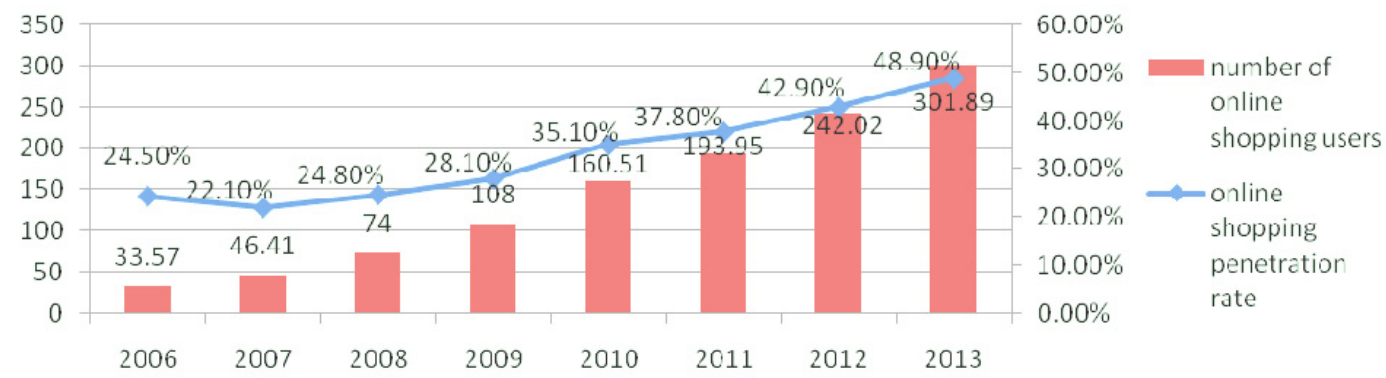

Figure 1. 2006-2013 number of online shopping users and penetration rates in China

Source: Chinese network shopping market report 2014 (user population of 1 million).

In 2013, the online shopping market continued to rapidly move forward, with transactions amounting to 1.85 trillion yuan, showing an increase of $40.9 \%$ over 2012 (See figure 2). Total online retail market transactions accounted for $7.9 \%$ of total retail sales of social consumer goods in 2013 .

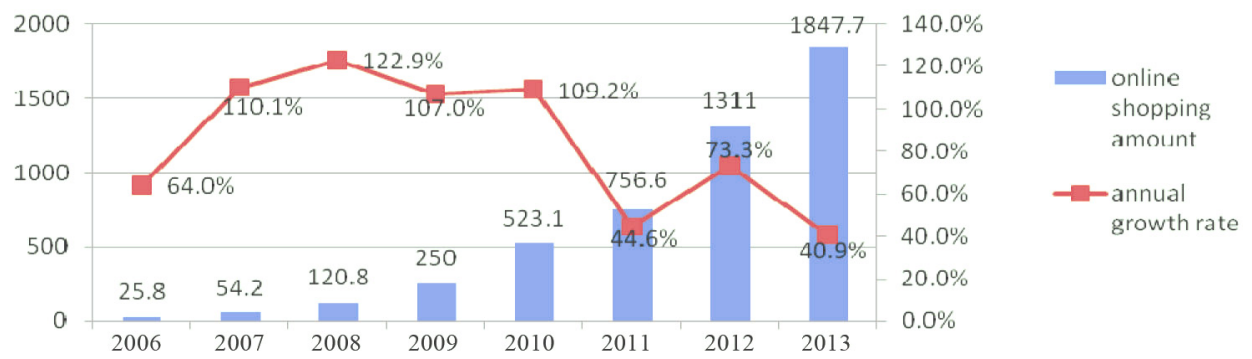

Figure 2. 2006-2013 amount of online shopping annual growth rates in China

Source: Chinese network shopping market report 2014 (amount in 1 billion yuan RMB). 
Currently, there are more than 200,000 international e-commerce companies of various platforms in Chinese territory. International e-commerce transactions in China amounted to 2 trillion yuan (RMB) in 2012, (including B2B and B2C), an increase of $25 \%$ over the previous year. According to incomplete statistics, in 2013 China's foreign trade e-commerce turnover is expected to exceed 3.1 trillion yuan, and in 2016, it will increase to 6.5 trillion yuan, with an average annual growth rate of nearly $30 \%$. In sharp contrast, in the past five years, the average annual growth rate of China's exports is less than $10 \%$.

As for China's international B2C market, in 2007 it reached 4 billion yuan, and then soared to 50 billion in 2009 . In 2011, Chinese overseas purchasing market transactions reached 26.5 billion yuan, representing an increase of $120 \%$ compared to 2010 . In 2012, overseas shopping transactions reached 48.3 billion yuan through e-commerce platforms, and in 2013 it reached more than 70 billion yuan (See figure 3). Several advantageous policies continue to be introduced in 2014, making international e-commerce retail even more appealing to consumers and businesses alike.

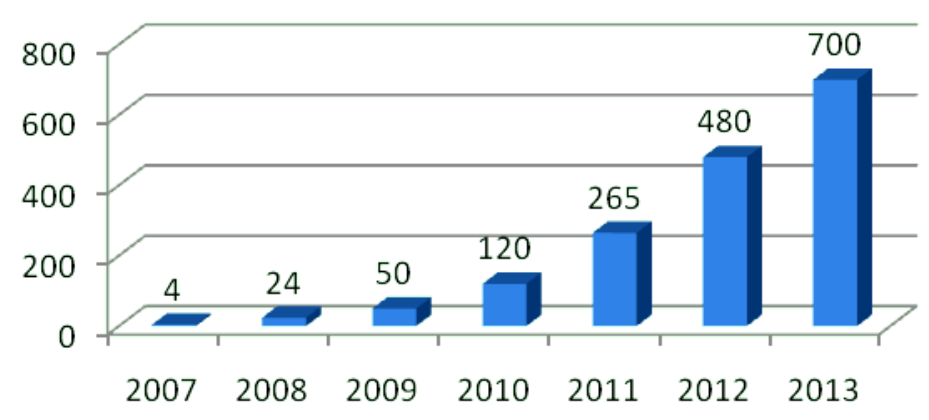

- amount of international ecommerce retail

Figure 3. Scale of international e-commerce retail

Source: China Electronic Commerce Research Center "2011 China B2C E-Commerce Market Research Report" (amount in 100 million yuan RMB).

\subsubsection{The Main Characteristics of Consumers and the Products}

The vast majority of consumers are highly educated, typically located in economically developed coastal cities, and have a strong demand for the products. Those with an undergraduate college degree accounted for $80 \%$ of international e-commerce consumers, which is likely due in part to the technical complexity of cross-border online shopping. Transaction data show that most purchased goods are closely associated with the daily necessities of life, such as cosmetics, powdered milk, clothing and electronic products. These are fast moving consumer goods, with a high frequency of repeat purchases. It is difficult to replace these with other commodities, and so the unyielding demand characteristics are clear.

\subsubsection{Analysis of the Driving Force of International Purchasing}

The reasons why the Chinese use offshore online shopping can be explained in three ways.

First, the product safety crisis arose following the milk scandal of 2008. Although the government has introduced a number of initiatives as a result, it has not regained public confidence in food safety. In 2013, the domestic sale of infant formula was over 200,000 tons, while the market share of foreign milk powder had more than $50 \%$. High national quality standards and sound legal systems in developed countries provide a sense of increased protection and a guarantee of brand quality, for which Chinese consumers are willing to pay.

Secondly, the total population of China reached 1360.72 million in 2013. GDP per capita in China has more than 10,000 U.S. dollars in six provinces, while the national average GDP is $\$ 6,750.1$ (See table 1). The number of domestic residents traveling abroad was more than 83 million in 2012, the amount of shopping was $\$ 102$ billion, per capita shopping spending of about 7,300 yuan, and the average annual growth in number and amount are more than 20\%. Based on the Innovation Diffusion model, the adoption of China's online shopping model will continue to expand in the near future, and part of the purchasing power is bound to shift to online shopping. 
Table 1. GDP per capita in top 6 provinces

\begin{tabular}{llllll}
\hline & Province & GDP/1 Billion RMB & Population/Million & GDP Per Capita /RMB & GDP Per Capita / US Dollar \\
\hline 1 & Tianjin & 1437.016 & 14.1315 & 101688.85 & 16419.44 \\
2 & Beijing & 1950.06 & 20.693 & 94237.66 & 15216.31 \\
3 & Shanghai & 2160.212 & 23.8043 & 90748.81 & 14652.98 \\
4 & Jiangsu & 5916.175 & 79.1998 & 74699.37 & 12061.51 \\
5 & Zhejiang & 3756.849 & 54.77 & 68593.19 & 11075.57 \\
6 & Neimenggu & 1683.238 & 24.8985 & 67603.99 & 10915.84 \\
& Nation & 56884.5 & 1360.72 & 41804.71 & 6750.1 \\
\hline
\end{tabular}

Source: National Bureau of Statistics of the People's Republic of China.

Lastly, there is a large gap in the prices of foreign brands in China and abroad, because of different channels, tariffs and various other reasons. Additionally, significant discounts will occasionally be offered on foreign discount sites, making overseas online shopping prices more competitive.

\subsection{Stages of Development of Offshore Online Shipping}

\subsubsection{The First Stage: Personal and Small Proxy Mode}

At this stage, online shopping has been booming in the country. However, there are also many obstacles for the majority of consumers, mainly due to language barriers and unfamiliarity with sites and shopping processes. There are two main modes of operation in this stage, one is direct shopping on the overseas platform, and the second is through agents; the latter is more common. Agents are usually individuals or small businesses, registered in the domestic shopping platform who accepts orders from consumers there, then purchase discounted products from foreign websites or through purchases in duty-free shops abroad. Products are then carried by an individual or by an agent's specialized transport, since the majority of overseas shopping site does not provide for cross-border distribution to China.

There are two main points consumers must consider. First, transaction costs are typically high. A lot of time is spent on comparing and trialing product sources, as the guarantee of the individual agents is uncertain. Some agents use fraudulent products to deceive consumers, which makes it difficult to safeguard their rights. Second, legal risks exist in this industry because many importing agents fail to pay taxes on their goods. If those goods are identified during a spot check at customs, the entire package is identified as contraband and confiscated, thus resulting in consumers losing their purchased products. However, many buyers still take the chance, as the tariffs of Chinese Customs is quite high (see table 2), and the risks of being checked is low.

Table 2. Samples of the entry goods tax

\begin{tabular}{lll}
\hline Category & $\begin{array}{l}\text { Import duty rates for individual } \\
\text { articles }\end{array}$ & $\begin{array}{l}\text { Duty rate for generally imported } \\
\text { articles }\end{array}$ \\
\hline luggage and bags & $10 \%$ & $29 \%$ \\
cosmetic & $50 \%$ & $78 \%$ \\
food and beverage & $10 \%$ & $35 \%$ \\
liquor & $50 \%$ & $95 \%$ \\
Watch (duty-paid value over 10 thousand) & $30 \%$ & $62 \%$ \\
\hline
\end{tabular}

Source: calculated according to the minimum tariff rates and the lowest consumption tax published by China's General Administration of Customs.

At this stage, the main driving force for consumers is the price. Significant discounts on overseas products that are tariff-free create an obvious price variance between the products sold online and those in the Chinese local market.

Currently, no one importer controls international transport, so service differentiation is not significant. However, as this industry grows, the one who can offer the best price and also ensure cargo security and reliability has the opportunity to dominate the market.

\subsubsection{The Second Stage: Development of Scale and Standardization}

In order to solve the abovementioned issues of tariffs imposed, import and export statistics and agent service quality, the Chinese government introduced a series of regulatory policies. The Ministry of Commerce issued a 
report entitled "Opinions on Supportive Policy to the Implementation of International E-Commerce Retail Outlet" in September 2013. The Chinese Customs issued a document entitled "Notice on International E-Commerce Bonded Import Mode Pilot Issues" in March 2014. Shanghai, Hangzhou, Ningbo, Zhengzhou, Guangzhou, Chongqing are approved to be the only six cities to take part in the model pilot, "Bonded Warehouse Import", while Shanghai FTA is leading the reform. Since then, international e-commerce has moved into a second phase, and will be developed in scale and standardization.

The "Bonded Warehouse Import" approach provides a direct delivery from a bonded warehouse to an individual buyer. It allows for products to be imported in mass quantities, and removes tariffs until the products are sent out from the warehouses. This system will significantly reduce logistical costs, allowing for product prices to be typically $20 \%-30 \%$ cheaper than the domestic market price. The risks will also be reduced as the platforms can provide tariff and payment services to avoid the products being seized, and all goods will go through formal procedures to ensure quality.

The essence of the second stage is a kind of domestic resource integration with the agents, e-commerce platform and logistics under favorable policies. It is a process of allowing consumers to clearly see the shopping chain and allowing government departments to achieve effective regulations. For consumers, the driving force to buy the products online is lowered risk and competitive prices, therefore making online shopping more cost-effective.

\subsubsection{The Third Stage: International Value Chain Integration}

Fundamentally, the development of international e-commerce is a conduit for modernization. The reason why international e-commerce attracts domestic consumers is that it provides consumers with more attractive products through value chain integration.

With the further development in the six pilot areas mentioned above, it is expected that after the appropriate policies for entry of foreign assets are in place, China's international e-commerce development will enter into the third stage, which is the international value chain integration generated by foreign capital.

At present, most local e-commerce suppliers take the traditional route of dealers or distributors to access products, instead of purchasing directly from factories. The integration of foreign suppliers will enhance the competitiveness of products.

At this stage, the one who controls overseas procurement and transport will likely be able to become firmly established in the market.

\subsection{Challenges of Offshore Online Shopping}

The Chinese e-commerce market represents a significant piece of the economic pie for overseas companies. Although the potential is huge, there are several obstacles to obtaining a share of this pie.

\subsubsection{Language}

International e-commerce providers encounter consumers from all over the world. Many different languages, cultures, religions and customs have made international e-commerce more complex.

A survey created by the Payvision Company and distributed to investors, business service providers, independent sales organizations, global payment service providers and online merchants showed that $29.5 \%$ of the companies intend to focus on neighboring markets or regions that have a common language. Approximately $70.3 \%$ of the surveyed companies believe that a common language is a powerful internal driving force to expand international e-commerce, second to neighboring countries sharing a common border. About $67 \%$ of the surveyed companies believe that partners that share a language and sales teams who share an understanding of local culture language could increase cross-border e-commerce profits. More than half of the companies believe that the task of establishing a commonality of language in order to meet the multilingual needs of users is extremely difficult.

\subsubsection{Customs}

Networks can only solve communications, but the flow of goods and capital between countries is still controlled by the inherent national system. Thus cross-border e-commerce is facing a dual structure, as the flow of information can be cross-border and the flow of goods and money can be cut off by borders. In this dual structure, e-commerce websites are free for consumers to buy foreign goods, but due to financial restrictions, the goods may be returned to their country of origin because customs have not been cleared. When the imports and exports are over an approved weight, and there is a requirement to report the goods name, type, quantity, and price, in order to obtain a permit, it becomes a great burden for the average consumer and online business. 
An international framework of standards for e-commerce is currently lacking. Some countries have a small import tax for personal items, but each country is different, and most countries do not systematically monitor this small import tax. Variation also occurs within countries, because of offering operational capacity and even different employees within sites.

\subsubsection{Supply Chain Defects}

International e-commerce supply chains, due to the nature of cross-border transactions, is not always smooth and has its own deficiencies, which will affect the consumer's shopping experience and can discourage buying behaviors.

Supply chain flaws include:

Cross-border logistical problems

The inadequate capacity of local delivery services often results in delays and a high rate of packages lost in the mail. Mailed goods that are not packaged properly, goods that are being exchanged, or goods that are detained are all at risk of being lost or damaged in the process.

\section{Difficulties with cross-border product returns}

As overseas delivery will take a significant amount of time, when consumers find problems (for example, the goods are damaged) upon receiving the goods, the period in which a return is allowed may have already passed, and they cannot make a complaint in their own country as there is likely no administration for such issues, resulting in the consumer taking a loss.

\subsubsection{Additional Risks of International e-Commerce}

There is no regulatory system governing the online businesses, so there is no transaction guarantee for consumers. Therefore, the certainty of product authenticity, all depends on the honesty and ethics of the online businesses. Additionally, when using credit cards as a payment method, the consumer may be put at risk for credit card fraud and other security violations.

\subsection{Opportunities for International e-Commerce in the Pilot Areas}

\subsubsection{The Facilitation of Import Procedures}

As of April 2014, the Shanghai Free Trade Zone, which includes Ningbo Meishan Bonded Port, Guangzhou Nansha Bonded Port, Chongqing Cuntan "Harbour Water + airport" Port, bonded logistics center in Zhengzhou, Hangzhou e-commerce cross-border industrial park, have all began an integrated approach to importing goods.

The six bonded imports pilot cities have full support of systems and optimization processes through an innovative approach to customs, inspection and quarantine, foreign exchange and other regulatory authorities. For example, in the Shanghai Free Trade Area, to ensure proper oversight and customs clearance, a workflow has been adopted that includes:

- an organized system for the clearance of imported goods,

- a paperless workflow model to automatically compare customs declarations and the payment information, logistics and order information, and;

- regulation points set in the pilot areas region, where customs checkpoints can be done directly in the warehouse.

Additionally, in order to facilitate cross-border trade and consumer business tax, customs duty will launch an online payment system, electronic storage and other convenient initiatives.

\subsubsection{Bonded Warehouses as the Foundation for Market Competitiveness}

Bonded warehouses and warehousing services will likely be the hub and foundation of competitiveness of each of the bonded imports pilot cities. With a $\$ 1$ million of goods, for example, storage in the free trade zone in Shanghai will save at least \$24 million in taxes. Currently, companies are looking into the layout of the region, looking to take advantage of bonded warehouse rental services to help create new growth points.

The demand for bonded warehouses will continue to grow in the pilot areas as they provide retailers with affordable warehousing options for overseas brands with an online operations base. The bonded warehouses and other logistical resources may become a hotspot for competition, which would provide a space for international e-commerce players to compete with local business. 


\subsubsection{Use Pilot Areas as a Basis for Expansion to the Mainland Market}

Although some smaller or newer oversea brands and retailers have a competitive advantage over their Chinese contemporaries, their marketing costs are still quite high as domestic retail channels within China are quite strong, with control in the hands of a very small number of interest groups. Because of this, the pilot areas have potential to provide a significant consumer market for them. Overseas sellers could minimize risks by using bonded imports to reduce logistical steps and costs, customs clearance and other transactions, while conducting online retail also contributing to the development of China's huge market.

\subsubsection{Future Supportive Policies}

The Chinese Customs Administration is currently studying a retail e-commerce providers' clearance management system to achieve "releasing by examine list and implement inspection in large batch" The AQSIQ also has an innovative cross-border e-commerce supplier inspection and quarantine supervision model for small quantities, multi-batch, direct, electronic characteristics of e-commerce retail, in which early intervention and other measures which will retroactively facilitate the regulation. Each of these signifies that customs cross-border shopping will continue to be more convenient as time goes on.

Hangzhou is expected to build an online test free trade zone. It is planned to gather e-commerce players, logistics, third-party payment companies and related data, together forming a single window platform, and facilitate information sharing.

Also, the Shanghai Free Trade Zone is trialing the registration of foreign non-bank financial institutions and other regional economic organizations required to integrate foreign currency funds from abroad. Further oncoming supportive policies may provide a way for foreign capital to participate in China's booming e-commerce retail.

\section{SWOT Analysis and Strategies}

According the SWOT analysis matrix, the overseas e-commerce business development advantages, weaknesses, opportunities and challenges in China's bonded import pilot areas for E-commerce have been analyzed, and a combination of appropriate strategies have been outlined.

\begin{tabular}{|c|c|c|}
\hline $\begin{array}{l}\text { External } \\
\text { Factors }\end{array}$ & $\begin{array}{l}\text { Strengths } \\
\text { S1: Huge online shopping market } \\
\text { S2: Chinese consumers have purchasing } \\
\text { power } \\
\text { S3: Demand for overseas products is rising } \\
\text { S4: Competitive brands }\end{array}$ & $\begin{array}{l}\text { Weaknesses } \\
\text { W1: Unfamiliar with local rules } \\
\text { W2: Lack of local marketing experience } \\
\text { W3: International product services are hard to } \\
\text { control } \\
\text { W4: High tariffs and other regulatory issues }\end{array}$ \\
\hline Opportunities & SO & WO \\
\hline $\begin{array}{l}\text { O1: Various support policies in pilot areas } \\
\text { O2: Supply chain is benefited by the pilot areas }\end{array}$ & $\begin{array}{l}\text { Using bonded warehouse to import (S1, } \\
\mathrm{O} 1, \mathrm{O} 3 \text { ) }\end{array}$ & $\begin{array}{l}\text { Invest in the companies in the pilot areas (W1, } \\
\mathrm{W} 2, \mathrm{O} 1)\end{array}$ \\
\hline $\begin{array}{l}\text { O3: Bonded imports have lower costs } \\
\text { O4: IT technology could enhance service } \\
\text { capabilities }\end{array}$ & $\begin{array}{l}\text { Carry out branding }(\mathrm{S} 3, \mathrm{~S} 4, \mathrm{O} 3) \\
\text { Using new IT technologies to carry out } \\
\text { targeted customer service (S2, O4) }\end{array}$ & $\begin{array}{l}\text { Strategic alliance with logistics companies } \\
\text { (W3, W4, O2) }\end{array}$ \\
\hline Threats & ST & WT \\
\hline $\begin{array}{l}\text { T1: Logistics over long distance } \\
\text { T2: Different languages and cultural values }\end{array}$ & $\begin{array}{l}\text { Establish fulfillment center in pilot areas } \\
(\mathrm{S} 1, \mathrm{~S} 2, \mathrm{~T} 1)\end{array}$ & $\begin{array}{l}\text { Establish outsourcing of platform and offline } \\
\text { services(W1, W2, T2) }\end{array}$ \\
\hline T3: Numerous local competitors & Research on customer needs(S3, S4, T2) & Establish logistics network(W3, T1) \\
\hline $\begin{array}{l}\text { T4: Pilot areas may attract more international } \\
\text { business }\end{array}$ & Implement $\mathrm{O} 2 \mathrm{O}$ strategy (S4, T3, T4) & $\begin{array}{l}\text { Integration of } \quad \text { resources } \\
\text { cooperation }(\mathrm{W} 2, \mathrm{~W} 4, \mathrm{~T} 3, \mathrm{~T} 4)\end{array}$ \\
\hline
\end{tabular}

With the support and backing of effective policy, importing cross-border online retail in China is expected to accelerate in the near future. Foreign e-commerce companies can take advantage of these policies to maximize profit and take part in Chinese e-commerce market, seize China's newest round of domestic economic surge. This strategy can be implemented in both short and long term phases.

In the short term, e-commerce companies should focus on researching consumer needs and the procedures of the pilot areas. On the one hand, companies could maximize brand force through researching targeted consumer needs, and maximizing local marketing and branding to build credibility for the product. As many overseas businesses lack knowledge of local culture and values, outsourcing for the construction of Chinese websites and offline services are recommended. Additionally, in order to take full advantage of favorable policies in the 
bonded import pilot areas, the utilization of bonded import warehouses will reduce costs and to provide consumers with better value for money.

In the long term, e-commerce companies should focus on integration of resources, including bonded resources, logistical resources and offline service resources. First, e-commerce companies should make full use of bonded import policies and tap into the opportunities in the bonded imported pilot areas. Second, in order to establish a stable logistics network, companies should establish strategic alliances with logistical companies to utilize those logistical resources. Third, without offline service, online shopping cannot fully win over consumers, and online to offline $(\mathrm{O} 2 \mathrm{O})$ services are generally considered as the future trend. Therefore, establishing an offline service network to achieve $\mathrm{O} 2 \mathrm{O}$ should be considered for the long run.

\section{Conclusion}

The rate of online shopping in China is increasing rapidly. The online shopping market is moving forward at an extreme pace, and the international B2C market has grown enormously in recent years. An analysis of online buyers and their purchasing power indicates growth will continue to be stable and sustainable in the future. As the three stages of development of offshore online shipping indicates the route of integration of resources, the e-commerce players should enhance ability to compete though the integration of resources and investment in business relationship. There is no doubt that the future lies in e-commerce, and that international companies should be quick to grab hold of the opportunities that pilot areas in China have to offer.

\section{References}

Alhorr, H. S., \& Singh, N. (2010). E-commerce on the global platform: Strategic insights on the localization-standardization perspective. Journal of Electronic Commerce Research, 11(1), 6-13.

Bieron, B., \& Ahmed, U. (2012). Regulating e-commerce through international policy: Understanding the international trade law issues of e-commerce. Journal of World Trade, 46(3), 545-570.

China Electronic Commerce Research Center. (2012). 2011 China B2C E-Commerce Market Research Report. Retrieved from http://www.100ec.cn/detail--6041566.html

Gupta, B., Iyer, L. S., \& Weisskirch, R. S. (2010). Facilitating Global E-Commerce: A Comparison of Consumers' Willingness to Disclose Personal Information Online in the US and in India. Journal of Electronic Commerce Research, 11(1), 41-52.

$\mathrm{http} / / / \mathrm{b} 2 \mathrm{~b}$. toocle.com/detail--6168415.html

http://www.customs.gov.cn/publish/portal0/tab3889/module1188/info362458.htm

http://www.stats.gov.cn/tjsj/

I-World Electronic Retailing Research. (2014). 2013 Chinese Network Shopping Market Report. Retrieved from http://wenku.baidu.com/view/06b44838aflffc4ffe47ace5.html

Lau Takwan. (2013). Seven Trends on Mobile Internet. Retrieved from http://wenku.baidu.com/view/cf02a615be1 e650e52ea9953.html

Timmers, P. (2000). Business Models for Electronic Markets.

Van Slyke, C., Lou, H., Belanger, F., \& Sridhar, V. (2010). The Influence Of Culture On Consumer-Oriented Electronic Commerce Adoption. Journal of Electronic Commerce Research, 11(1), 30-40.

Williams, C., \& Martinez, C. A. (2010). National institutions, entrepreneurship and global ICT adoption: A cross-country test of competing theories. Journal of Electronic Commerce Research, 11(1), 73-91.

Wu, B. (2006). New Features in International and the Strategies for International E-Commerce Business. Liaoning Economy.

Xiong, Y. (2007). Online Shopping Market "Price Dispersion" Phenomenon Analysis and Business Strategy Choice. Price Theory and Practice.

\section{Copyrights}

Copyright for this article is retained by the author(s), with first publication rights granted to the journal.

This is an open-access article distributed under the terms and conditions of the Creative Commons Attribution license (http://creativecommons.org/licenses/by/3.0/). 